\section{Gêneros textuais e ensino: uma análise do livro didático de língua portuguesa do ensino secundário da $12^{\mathrm{a}}$ classe de Angola}

Textual genre and teaching: an analysis from Portuguese language high school book from the 12th class from Angola

Léia Cruz de MENEZES (UNILAB) leiamenezes@unilab.edu.br Jeremias Abel Graciano BOIO (UNILAB) jeremiaslavista@gmail.com

\title{
00000000000
}

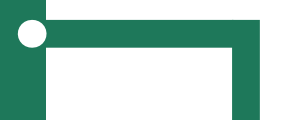

MENEZES, Léia Cruz de; BOIO; Jeremias Abel Graciano. Gêneros textuais e ensino: uma análise do livro didático de língua portuguesa do ensino secundário da $12^{\mathrm{a}}$ classe de Angola. Entrepalavras, Fortaleza, v. 7, p. 517-533, ago./dez. 2017.

Resumo: Na perspectiva de uma educação linguística capaz de tornar as pessoas mais críticas, participativas e atuantes socialmente, entende-se a necessidade de um trabalho didático-pedagógico com uma língua-em-função, o que só é possível se tomarmos como objeto os gêneros textuais. A partir dessa premissa, este artigo objetiva analisar como o livro didático adotado na $12^{\mathrm{a}}$ classe em Angola aborda os gêneros textuais. Como aporte teórico, utilizaremos os trabalhos de Antunes (2003), Marcuschi (2010) e Rojo \& Barbosa (2015). Constatamos que, embora a obra Língua portuguesa$12^{a}$ classe, de Olga Magalhães, Fernanda Costa e Lília Silva, explore vários gêneros textuais, as atividades sugeridas a partir dos gêneros são, não raro, exercícios mecânicos de treinamento escolar da escrita ou da oralidade, pois desvinculados de situações reais de uso.

Palavras-chave: Gêneros textuais. Ensino. Livro didático. 
v. 7 (2) 517-533 ago/dez 2017

Abstract: Adopting the perspective of a linguistic education able to make people more critical, participative and socially active, it is necessary a didactical-pedagogical work with a language-in-function, that is possible only when text genres are considered as objects. From that standpoint, this paper aims to analyze hoe the didactical book used in the 12th period in Angola approaches text genres. Theoretical framework was based in authors as Antunes (2003), Marcuschi (2010) and Rojo \& Barbosa (2015). It was realized that although the book Língua portuguesa-12a classe, by Olga Magalhães, Fernanda Costa and Lília Silva, explores several text genres, the suggested activities based on genres are, not rarely, mechanical exercises for school training of writing or speech, unlinked to real situations of usage.

Keywords: Text genres. Teaching. Didactical book.

\section{Introdução}

O contexto de ensino da língua portuguesa em Angola enfoca a língua como estrutura potencial, por isso são frequentes as atividades que privilegiam análises de frases descontextualizadas e memorização de nomenclaturas gramaticais. Segundo Garcia Neto (2009, p.2):

As aulas de língua portuguesa têm sido repetitivas, quanto ao conteúdo e metodologia, desde os primeiros níveis até o ensino médio, provocando a falta de interesse e motivação nos alunos.

Durante o Curso de Letras na Unilab, demo-nos conta de que a formação para o exercício da cidadania, como defende Antunes (2003), exige um trabalho linguístico com a língua-em-função, portanto, a partir da perspectiva dos gêneros textuais. Começamos, então, a olhar para o ensino dos países cuja língua oficial é a portuguesa - nosso foco aqui é Angola - em outra perspectiva, e perguntas foram sendo suscitadas. Uma delas, a que pretendemos responder nesse trabalho é quanto aos livros didáticos atualmente adotados no ensino em Angola: será que estão adequados à perspectiva de trabalho com a língua-em-função? A fim de começarmos a responder essa indagação, empreendemos análise do livro Língua portuguesa $-12^{a}$ classe, de Olga Magalhães, Fernanda Costa e Lília Silva.

Destacamos que, no âmbito das políticas de reconstrução e desenvolvimento da República de Angola, a Reforma do setor da Educação é entendida como de importância crucial. Um dos objetivos da Reforma Educacional implementada no ano letivo de 2003 e com avaliação dos resultados em 2012 concerne à "Melhoria da qualidade e quantidade de manuais escolares" (MEDANGOLA, 2010, p. 06). Nosso trabalho, portanto, intenciona investigar se esse objetivo da Reforma foi alcançado no que diz respeito ao material didático de língua portuguesa. 
Este artigo encontra-se dividido em quatro seções. Logo após essa introdução, procedemos à descrição geral do livro objeto de análise e à contextualização da reforma educacional em Angola. Na sequência, refletimos sobre a conceituação de gênero textual, bem como ponderamos acerca da relevância de uma educação linguística a partir de um trabalho didático com os gêneros textuais. Após essa seção teórica, procedemos à análise de atividades de escrita e oralidade propostas pelo livro didático adotado na $12^{\mathrm{a}}$ classe de Angola. Por fim, refletimos sobre o que percebemos em nossa análise a partir dos estudos sobre gêneros textuais e ensino que consultamos.

\section{O livro didático de língua portuguesa em análise e o contexto escolar de Angola}

O livro didático intitulado Língua Portuguesa $-12^{a}$ classe, de Olga Magalhães, Fernanda Costa e Lília Silva, publicado pela Porto Editora (doravante, LDP), contém 224 páginas distribuídas em três unidades temáticas. No final de cada unidade, encontra-se uma ficha informativa, na qual constam propostas de oficinas de escrita e atividades de interpretação de textos em seção intitulada ler e compreender. No final do livro, tem-se a subseção denominada bloco informativo, voltada para o estudo da gramática. A organização geral do LDP em apreciação aponta para um ensino de língua materna marcadamente fragmentado em três (sub) disciplinas - Leitura, Redação e Gramática, com ênfase em gêneros da literatura, esses servindo de fontes para exemplos e proposição de atividades.

A primeira unidade do livro é denominada texto literário e seu conteúdo está organizado nos seguintes tópicos: "o texto literário e não literário", "versificação" e "arte e beleza fazem o verdadeiro escritor". Nessa unidade, encontramos poemas, crônicas, contos e poesias de diversos autores angolanos, nomeadamente: Luís Kandjimbo, Roderick Nehone, Antero Abreu, Cristovão Neto, Conceição Cristovão, Uhanhenga Xitu, entre outros. Nessa unidade, propõe-se a escrita dos gêneros curriculum vitae, entrevista, relatório e carta de apresentação, com instruções específicas para a produção dos referidos gêneros.

Destacamos que, nessa unidade, as oficinas de escrita que exploram os gêneros curriculum vitae, entrevista e carta de apresentação estão atreladas a um dos textos literários constantes na unidade, pois ele contém, ao seu término, um anúncio. A partir desse anúncio, 
as oficinas de escrita propõem a criação dos gêneros que citamos. Registramos que há informações detalhadas sobre o curriculum vitae, a carta de apresentação e a entrevista de emprego.

A segunda unidade é denominada texto argumentativo e está organizada nos seguintes tópicos: "artigo de opinião", "entrevistas", "provérbios". Nessa unidade, contemplam-se a literatura oral angolana, crônicas, cartum e excertos de romances de autores angolanos, dentre os quais: Boaventura de Sousa Santos, Hugo Santos, António Mega Ferreira, Luís Kandjimbo. A unidade se inicia com uma seção denominada "recorda", em que os autores apresentam alguns conceitos básicos acerca do texto argumentativo e relembram algumas regras da argumentação, os tipos de argumentação e a forma com que os textos se organizam. Essa seção é intitulada recorda porque os livros das classes anteriores, produzidos pelos mesmos autores, abordam argumentação. Há ainda orientações para execução de um trabalho de pesquisa a partir da problematização da dificuldade que os alunos têm com a leitura.

A terceira unidade, denominada texto dramático, está subdividida em "introdução ao gênero dramático" e "apresentação das modalidades deste gênero", a saber: tragédia, drama, comédia, farsa e tragicomédia. Na sequência, são apresentadas instruções sobre o que é necessário para a escrita de peça teatral e de banda desenhada (tirinhas no Português Brasileiro). A unidade contém apresentação de novelas de autores angolanos: José Mena Abrantes, José Rodrigues Miguel, Manuel Rui e de um autor português, José Rodrigues Miguéis. Essa seção do livro é composta de orientações que têm a finalidade de preparar o aluno para o teatro, tais como: exercícios de leitura expressiva, exercícios de expressão corporal e exercícios de improvisação.

A última parte do livro é denominada de bloco [in]formativo. Unidade dedicada à gramática, que aborda as seguintes temáticas: classes de palavras (substantivos, adjetivos, pronome, verbo e advérbios); funções sintáticas (elementos essenciais e outros elementos da oração); coordenação e subordinação; pontuação; ortografia; fatores de textualidade (coesão e coerência textuais, discurso direto, indireto e indireto livre e tipologias textuais) e figuras de estilo. Encontramos ainda glossário de termos literários. No final da apresentação de cada ponto gramatical, há exercícios de fixação da nomenclatura gramatical em frases isoladas.

As atividades de escrita propostas, a partir dos diversos textos constantes nas unidades, situam-se nas oficinas de escrita. Por sua 
vez, as atividades de compreensão leitora estão situadas na seção ler e compreender. Há articulação entre as duas seções, de modo que os textos nos quais a compreensão leitora é explorada subsidiam as atividades de desenvolvimento da escrita.

Após essa visão geral do livro didático em apreciação, destacamos, para efeito de contextualização, alguns fatores sociopolíticos que resultaram na implementação deste LDP em Angola.

Após 27 anos de Guerra civil em Angola, o que corresponde ao período de 1975 a 2002, o Ministério da Educação (MED), em parceria com a UNESCO, implementou o projeto da Reforma Educativa, com o objetivo de melhorar a qualidade de ensino do país. Foram três fases para a implementação deste projeto: a fase da emergência (20032006), a fase da estabilização (2007-2011) e a fase do desenvolvimento (2012-2015). A reforma educativa surgiu com vistas a responder os desafios sobre o acesso e a qualidade nos subsistemas que integram a Alfabetização, o Ensino de Adultos, o Ensino de Base Regular, o Ensino Médio (normal e técnico-profissional) e o Ensino Superior.

Com a Reforma Educativa, surgem mudanças nos livros didáticos em todos os níveis de escolaridade. O LDP em análise entrou em vigor na fase da estabilização (2007-2011) e permanece em uso em 2017. O processo de implementação da Reforma no sistema de educação de Angola é importante para a compreensão do atual estado da educação. Os dados do Instituto do Bem-estar da População (IBEP) estimam que $58,5 \%$ das crianças e adolescentes dos 12 aos 17 anos frequentam o ensino primário, em vez de estarem cursando o ensino secundário, e isto revela o alto nível de atraso escolar que se registra em Angola.

De acordo com o MED, a faixa etária ideal para frequentar o ensino de base é dos 6 aos 12, e, para o Ensino Médio, a faixa etária é dos 13 aos 17 anos. Esses dados não correspondem à realidade do país. Os dados do IBEP revelam o atraso escolar em Angola, principalmente nas regiões distantes das capitais de cada província.

Embora os autores dos livros didáticos sejam angolanos, a produção de livros didáticos dá-se em Portugal e a variante do português presente nos livros é a europeia. No LDP em análise, apenas na unidade sobre os textos literários é que encontramos marcas linguísticas do português falado em Angola. Além de ignorar as marcas do português angolano, destacamos ainda que a língua portuguesa não é acessível a muitos alunos, principalmente os que residem nas regiões distantes das cidades, pois não têm o português como língua materna. 
v. 7 (2) $517-533$ ago/dez 2017

Após essa visão geral do livro didático no contexto de Angola, consideraremos o conceito de gênero textual, bem como a relevância de um trabalho didático-pedagógico a partir dos gêneros textuais. A fim de, no tópico subsequente, voltarmos nossa atenção ao livro didático adotado na $12^{\mathrm{a}}$ classe de Angola e analisarmos como o material propõe o trabalho com a escrita. A $12^{\text {a }}$ classe de Angola é o último ano do Ensino Médio angolano, o que equivale ao nosso $3^{\circ}$ ano do Ensino Médio.

\section{Gêneros textuais e ensino}

Quando nos comunicamos, quer oralmente, quer por escrito, estamos produzindo um gênero textual. Os estudos sobre os gêneros são antigos, começaram na Grécia, com Platão e Aristóteles, com enfoque nos gêneros literários. Marcuschi (2010, p.31) afirma que

[...] o estudo dos gêneros existe no ocidente há muitos anos, mas com ênfase na literatura, na atualidade estas discussões atravessaram as fronteiras da literatura e abarcam categorias distintas dos discursos orais e escritos.

Segundo Rojo \& Barbosa (2015, p. 36), "Platão aponta três gêneros literários que apresentam especificidades: o épico, o lírico e o dramático". Enquanto na Poética o conceito de gêneros estava ligado à literatura, na Retórica, Aristóteles traz uma concepção ligada aos gêneros retóricos (deliberativo ou político, forense ou judicial e demonstrativo ou epidítico), o objetivo desses gêneros era preparar as mais variadas formas de participação ética e efetiva na vida da cidade (Pólis).

Bakthin e seu círculo de discussões, integrado por Valentin Volochinov e Pavel Médvédev, empreenderam reflexão sobre os gêneros de texto e dos discursos, tanto na vida prática como na arte. Atualmente, com a expansão dos gêneros orais e escritos em decorrência das demandas comunicativas do século XXI, é crescente também o interesse em compreendê-los e estudá-los.

Em relação à conceituação de gêneros textuais, destacamos a conceituação de Marcuschi, assumida nesse trabalho:

gênero textual são textos materializados que encontramos em nossa vida diária e que apresentam características sociocomunicativas definidas por conteúdos, propriedades funcionais, estilo e composição característica. Se os tipos textuais são apenas meia dúzia, os gêneros são inúmeros. Alguns exemplos de gêneros textuais seriam: telefonema, sermão, carta comercial, carta pessoal, romance, reportagem jornalística, aula expositiva, reunião de condomínio, noticia jornalística [...] (MARCUSCHI, 2010, p.23). 
Rojo \& Barbosa (2015) tecem o seguinte comentário ao conceituar gêneros textuais, diferenciando-os do que chama de tipos de texto:

Tipos de texto são classes, categorias de uma gramática de texto - portanto, "uma construção teórica" que busca classificar os textos com base em suas características linguísticas (léxico, referenciação, sintaxe, relações lógicas de coerência e coesão, tipos e tempos de verbos, natureza de composição). Gêneros textuais, não são classes gramaticais para classificar textos: são entidades da vida. (ROJO \& BARBOSA, 2015, p. 26-27).

Como fenômenos sociais, históricos e culturais, portanto, não existe uma lista fechada de gêneros. Os gêneros não são, em tese, quantificados porque são infinitas as formas de interação humana. Para cada situação existem diferentes formas linguísticas que viabilizam a socialização. Nesse sentido, entendemos que a apropriação de gêneros é indispensável à competência comunicativa.

Ao longo da escolarização formal, os alunos precisam compreender que os gêneros variam quanto à natureza da informação, ao conteúdo vinculado, ao nível de linguagem, à relação entre os participantes e os objetivos comunicativos. Os gêneros possuem características que os definem, tais como a construção composicional, o conteúdo e o estilo. De acordo com Marcuschi (2010, p. 37), "os gêneros textuais não são frutos de invenções individuais, mas formas socialmente maturadas em práticas comunicativas". Na sua composição, os elementos linguísticos devem estar adequados e ajustados para que o leitor consiga reconhecer o gênero por sua construção composicional, seu conteúdo e estilo.

No que tange aos textos em circulação na escola: os chamados "gêneros escolares", produzidos, em geral, com objetivos de obtenção de notas, Rojo \& Barbosa (2015) faz a seguinte consideração:

Esses tipos de texto mais conhecidos - descrição, narração, dissertação/argumentação, exposição e injunção - vêm sendo ensinados e solicitados nas escolas há pelo menos centenas de anos, o que faz deles gêneros escolares, que só circulam lá para ensinar o "bem escrever". (ROJO \& BARBOSA, 2015, p.26)

Entendemos que, quando restringimos o ensino de língua portuguesa aos "gêneros escolares", privamos os alunos do contato com a língua-em-função. Segundo Antunes (2003, p. 26), "éna escola que as pessoas exercitam a linguagem que não diz nada”. Esta linguagem não diz nada porque não é língua em uso, por isso esse tipo de trabalho priva o aprendente de compreender a complexidade das realizações linguísticas. Acerca dessa complexidade, lemos em Antunes (2003): 
v. 7 (2) $517-533$ ago/dez 2017

Os gêneros de textos evidenciam essa natureza altamente complexa das realizações linguísticas: elas são diferentes, multiformes, mutáveis, em atendimento à variação dos fatores contextuais e dos valores pragmáticos que incluem e, por outro lado são prototípicas, são padronizadas, são estáveis, atendendo à natureza social das instituições sociais a que servem. (ANTUNES, 2003, p. 50).

A escola tem encontrado seu limite no trabalho com os chamados "gêneros escolares". Estes gêneros tendem a inibir a criatividade dos alunos quanto à produção de outros gêneros que façam sentido de acordo com a realidade deles. Não queremos menosprezar as atividades envolvendo os gêneros escolares que constam em materiais didáticos, mas o avanço dos estudos linguísticos nos faz pensar em um ensino de língua portuguesa que motive os alunos a produzirem não apenas redações que servem para concessão de notas, cujo único leitor é o professor, mas textos orais e escritos relevantes, por meio dos quais se possa adquirir habilidades para responder aos mais variados propósitos comunicativos.

A viabilização da atividade de produção dos diferentes gêneros em nossas escolas requer levar em consideração os processos inerentes à escrita, o que envolve algumas etapas que a antecedem e precedem para que nossas produções textuais sejam relevantes. Em muitos casos, os alunos são postos diante de práticas de escrita sem nenhuma forma de orientação e sem previsão de retorno das atividades propostas. Nossas escolas por vezes realizam atividades pouco desejáveis, em que as chances para elaborar um texto que não sirva apenas de avaliação é quase inexistente. De acordo com Antunes (2003, p. 54-55), "a escrita compreende etapas distintas e integradas de realização que são: planejamento, escrita e revisão".

Na primeira etapa, a do planejamento, são tomadas importantes decisões: delimitação do tema, definição dos objetivos e escolha do gênero que melhor se adequa às intenções comunicativas. Esta primeira fase é quando se dão as decisões sobre o "que dizer", "para que dizer" e "para quem dizer", esse é um momento que define as demais partes do trabalho de produção textual.

A segunda etapa, a da escrita, é o resultado do que foi registrado no planejamento; neste momento, quem escreve vai construindo o objeto projetado na etapa anterior. Nessa fase, são importantes a escolha lexical e a ordem sintático-semântica, que deverão estar em consonância com a situação de comunicação. Caso a etapa do planejamento considere a 
realidade social do aluno, o projeto de trabalho e, principalmente, a etapa da escrita, trará motivação ao ser executada, pois o aluno não estará envolvido numa realidade de escrita alheia a sua realidade.

A última etapa, a da revisão, é a fase em que a escola quase sempre ignora, substituindo-a pela avaliação por parte do docente, apenas para fins de atribuição de nota, sem qualquer retorno que objetive uma melhoria significativa no trabalho realizado pelo aluno. Esse seria o momento adequado para aprimorar a escrita, ajudando o aluno a construir um todo significativo. Sabemos que a etapa da revisão do que foi escrito é oportuna para que sequências didáticas sejam pensadas como resposta às deficiências que os alunos apresentaram, quer na etapa do planejamento quer na etapa da escrita.

Na realidade de Angola, a LDB (Lei de Bases do Sistema da Educação) reconhece que é através da educação que o indivíduo poderá atuar em diversas áreas da sociedade, adequando-se a diferentes e variados contextos:

A educação constitui um processo que visa preparar o indivíduo para as exigências da vida política, económica e social do País e que se desenvolve na convivência humana, no círculo familiar, nas relações de trabalho, nas instituições de ensino e de investigação científico - técnica, nos órgãos de comunicação social, nas organizações comunitárias, nas organizações filantrópicas e religiosas e através de manifestações culturais e gimno-desportivas. (LDB/ANGOLA, 2001, p.2).

Se há a compreensão de que o papel da escola é formar o aluno para exigências das diversas áreas do país; logo, as aulas de língua portuguesa são muito importantes nesse projeto educacional, não podendo ser alicerçadas, por exemplo, em análise de frases descontextualizadas, pois assim, o objetivo não será alcançado: a preparação de indivíduos para as exigências da vida política, econômica e social do País. Ressaltamos também que os professores, para alcançarem esse objetivo de formar cidadãos, não podem se limitar aos livros didáticos, antes "o professor precisa ser visto como alguém que, "[...] com os alunos, pesquisa, observa, levanta hipóteses, analisa, reflete, descobre, aprende e reaprende", como bem afirma (Antunes, 2003, p.108).

Voltemos agora nossa atenção ao livro didático utilizado na $12^{\mathrm{a}}$ classe de Angola a fim de analisarmos a perspectiva de trabalho com os textos nele constante. 
v. 7 (2)

$517-533$ ago/dez 2017

\section{0 trabalho textual proposto pelo livro didático em análise}

O primeiro aspecto que nos chama atenção concerne à diversidade de gêneros textuais constantes no LDP: entrevista, relatório, cartoon, banda desenhada, poema, biografia, peça teatral, crônica, novela, romance e curriculum vitae. Outro aspecto que nos despertou atenção diz respeito à divisão didática do livro, que nos remete aos gêneros clássicos da literatura: épico, lírico e dramático. Assim, a vertente literária é predominante na escolha dos textos nas várias unidades do LDP. Destacamos que essa predominância de textos literários cumpre um dos objetivos da reforma Educativa de Angola, pois uma das inovações concerne à inserção da "Literatura Angolana na 11. ${ }^{\text {a }}$ classe e Literatura Universal na 12. "classe" (MEDANGOLA, 2010, p. 08).

Em relação ao tratamento concedido às sequências textuais constitutivas dos gêneros, observamos que elas - denominadas no LDP de "protótipos textuais" - são apresentadas na última seção do livro, denominada de bloco informático, parte da obra cujo foco são os aspectos gramaticais. Entendemos que essa opção didática é problemática, pois a percepção de que as sequências textuais são constitutivas dos gêneros textuais se perde facilmente. Ao longo das oficinas de escrita, que exploram os gêneros, os alunos trabalham gêneros sem a percepção clara das sequências que os constituem, pois apenas no final da obra terão acesso a elas.

Selecionamos algumas atividades propostas no livro Língua Portuguesa - $12^{a}$ classe, a fim de observarmos a perspectiva de texto a elas subjacente. Para nortear nossa análise, tomamos por base a seguinte indagação: os encaminhamentos propostos nas oficinas de escrita comtemplam a perspectiva de uma escrita com função social, o que é condizente com a perspectiva dos gêneros textuais?

No início da primeira unidade, os autores apresentam noções prévias do texto literário, em que lemos o seguinte:

Quadro 01 - Distinção entre Texto não literário e Texto literário

\begin{tabular}{|l|l|}
\hline \multicolumn{1}{|c|}{ Texto não literário } & \multicolumn{1}{c|}{ Texto literário } \\
\hline $\begin{array}{l}\text { Principal intenção: utilitária } \\
\text { (informar) }\end{array}$ & Principal intenção: estética (provocar prazer) \\
\hline Visão objetiva do mundo & \\
\hline & Linguagem mais elaborada \\
\hline $\begin{array}{l}\text { Predomina a denotação: as palavras } \\
\text { são usadas sem duplos sentidos }\end{array}$ & $\begin{array}{l}\text { A conotação é muito importante: palavras e } \\
\text { frases podem admitir vários significados }\end{array}$ \\
\hline & Língua cuidada \\
\hline
\end{tabular}

Fonte: Magalhães, Costa e Silva (2008, p.11). 
Essa definição no início da unidade justifica-se devido à existência, dentro dessa unidade, de gêneros como curriculum vitae e entrevista, que, de fato, caracterizam-se por uma intenção utilitária, pelas palavras denotativas e por apresentarem uma visão objetiva do mundo. Mas entendemos que, após essa conceituação geral, deveria haver detalhamento das caraterísticas dos gêneros constantes na unidade - entrevista, curriculum vitae, poemas, romances, biografia -, que levasse em conta seus respectivos conteúdos, composição e estilo.

Seria importante essa observação no LDP porque são gêneros que aparecem ao longo das unidades. A falta de informação referente aos gêneros apresentados na primeira unidade - os quais serão recorrentes ao longo do LDP - dificulta a realização das atividades escritas propostas na obra. Nem mesmo nas proposições de atividades com os gêneros há menção aos aspectos composicionais que os caracterizam, o enfoque restringe-se às questões gramaticais, conforme podemos constatar no exemplo a seguir:

Quadro 02 - Atividade cujo foco é metalinguagem da Gramática Tradicional

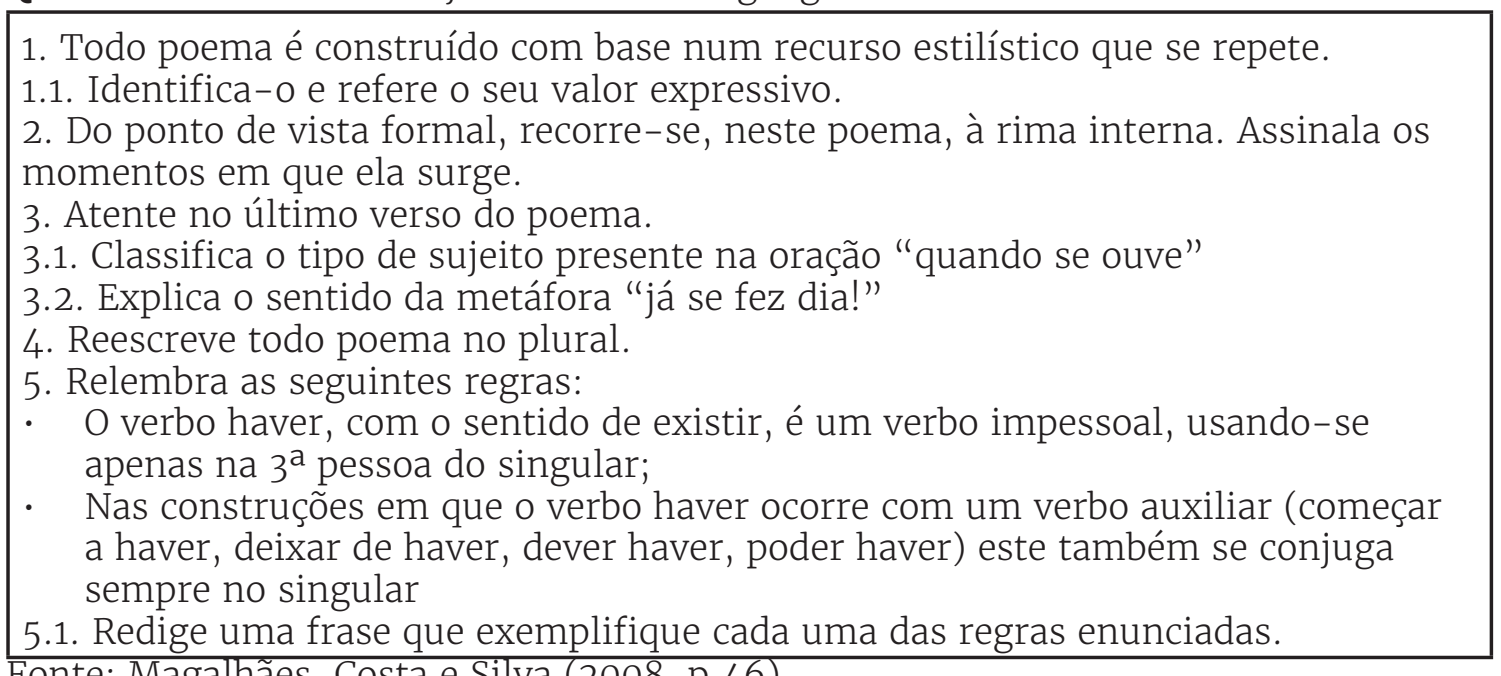
Fonte: Magalhães, Costa e Silva (2008, p.46).

Destacamos como ponto positivo a articulação entre o conteúdo dos textos constantes nas unidades e as oficinas de escrita, pois as propostas de escrita se embasam nas informações constantes nos textos. A oficina de escrita que veremos a seguir partiu da leitura de uma entrevista do escritor Roderick Nehone, constante no LDP. 
v. $7(2)$ $517-533$ ago/dez 2017

Quadro 03 - Exemplo de atividade de produção textual com base em texto constante no LD

\begin{tabular}{l}
\multicolumn{1}{c|}{ Oficina de Escrita $\mathbf{1}$} \\
$\begin{array}{l}\text { 1. "Angola é um país demasiado rico para que tenha um povo num nível perigoso } \\
\text { de ignorância. As riquezas que Angola tem são tais que nós estamos condenados a } \\
\text { deixar de ser ignorantes". }\end{array}$ \\
$\begin{array}{l}\text { 1.1 Num texto expositivo-argumentativo, que tenha entre } 100 \text { e } 150 \text { palavras, } \\
\text { comente a opinião expressa por Roderick Nehome no excerto acima. }\end{array}$
\end{tabular} Fonte: Magalhães, Costa e Silva (2008, p.28).

A proposta de escrita acima permite que os alunos reflitam sobre a realidade de Angola e concede ao docente espaço para que uma plenária seja aberta, viabilizando interlocução sobre assuntos que afetam o dia a dia do povo angolano. Além disso, a entrevista que serve como texto motivador para a atividade de escrita contém subsídios para a escrita proposta. Nossa crítica concerne à solicitação feita: a produção de um texto expositivo-argumentativo. Entendemos que seria oportuna a solicitação de um gênero textual por meio do qual é possível tecer comentários acerca da fala de outrem, expondo assim nossa opinião, o que poderia ser feito por meio de um artigo de opinião, por exemplo. Além disso, um meio real de vinculação dos textos dos alunos poderia ser proposto - em um Blog da escola, por exemplo. No entanto, foi solicitada a redação escolar, que serve apenas para fins de avaliação, pois não existe em outro meio de circulação, nem mesmo entre os membros da comunidade escolar.

Destacamos ainda que, no caso da entrevista do escritor Roderick Nehone, transcrita no livro, há informações a respeito do gênero entrevista: definição do gênero, passo a passo da realização de uma entrevista - etapas que a antecedem, o momento da entrevista em si e as etapas que a sucedem. Assim sendo, talvez fosse bem mais coerente que a oficina de escrita solicitasse aos alunos a elaboração de uma entrevista com um professor ou com alguém da família, por exemplo, na qual se extraísse do entrevistado posicionamento sobre a opinião expressa por Roderick Nehome. Assim, o aluno experienciaria estar na posição de entrevistador e redator, e as entrevistas poderiam ser publicadas no jornal da escola ou em murais. Essa tarefa daria ao aluno a oportunidade de exercitar as etapas da entrevista apresentadas no livro.

Passemos, na sequência, à análise de uma segunda oficina de escrita: 
Quadro 04 - Exemplo de oficina de escrita

\section{Oficina de Escrita 2}

"Vais, agora, escrever um artigo de opinião acerca da relação entre povos colonizadores e colonizados".

- Antes de começares a redigir o teu texto, procura:

- Anotar várias ideias que te surjam acerca deste tema;

- Selecionar a ideia-chave que vais querer desenvolver;

- Recolher diversos argumentos que sustentam as tuas ideias;

- Prever vários contra-argumentos.

Ao redigires o teu texto, utiliza uma linguagem direta e concisa; escreve frases simples; diz o que pensas claramente em insinuações; crie título que desperte o interesse e a curiosidade do leitor.

Organiza o teu texto em três partes distintas:

- Introdução - vai directo ao assunto, começando pelo essencial. Apresenta com clareza a ideia principal;

- Desenvolvimento- desenvolve a ideia principal, expondo argumentos persuasivos e rebatendo possíveis contra-argumentos. Tenta fazer uma citação de algum escritor ou conhecedor do tema;

- Conclusão- deves retomar a ideia principal, de forma mais convincente, uma vez que já foi fundamentada no desenvolvimento.

Boaventura de Sousa Santos, in visão, 17 de janeiro e 2008 (adaptado e com supressões).

Fonte: Magalhães, Costa e Silva (2008, p.65).

Essa oficina de escrita é antecedida por um artigo de opinião do escritor Boaventura de Sousa e Santos, intitulado AÁfrica e a Europa. Assim, o tema proposto para a escrita está em consonância com a temática do texto que já deve ter sido objeto de discussão e de leitura entre docentes e discentes, antes que a escrita seja solicitada. Antes do artigo de Boaventura, há explicação sobre o artigo de opinião. Desse modo, observamos que a unidade do LDP explora o gênero artigo de forma didática: conceituação - ilustração - pedido de escrita. Mas o objetivo da produção, a finalidade da escrita do artigo, o para quem escrever e para que escrever não estão postos. Assim, deixamos de ter um trabalho na perspectiva do gênero textual, que passou a ser tão artificial quanto a redação escolar. Esse é o ponto: como atividade socialmente situada, o trabalho com o gênero textual precisa ter função social.

A atividade precisa cumprir função sociocomunicativa, que pode ser entre as pessoas da própria escola ou entre as pessoas da escola e a comunidade fora dela. Seria oportuna uma prática de escrita em que os alunos pudessem observar seus trabalhos valorizados, para além da atribuição de uma nota.

Passemos, na sequência, à análise de uma terceira oficina de escrita, referente à unidade 03, cuja base é o conto do escritor português José Rodrigues Miguéis: 
v. $7(2)$

$517-533$ ago/dez 2017

\section{Oficina de escrita 3}

1.1. A atividade que agora te propomos - redação de um texto dramático - deverá ser realizada em grupos e envolve os seguintes passos:

a. Interpretação do excerto acima: identificação das personagens, do espaço, da situação.

b. Invenção da sequência e da conclusão da história, redigindo os diálogos e as indicações cénicas apropriadas.

c. Preparação da leitura expressiva dos diálogos e da movimentação em cena.

d. Apresentação do trabalho de cada grupo à turma.

Consideramos positiva a relação clara entre a proposta de escrita e o texto que precede a proposta. Aqui também salientamos o fator "criatividade", pois o aluno terá de recriar cenas apresentadas no texto que antecede a proposta de escrita, colocando-se como autor. Por se tratar de peça teatral, a atividade transcende o escrito e se completa com a dramatização proposta - que envolve leitura e movimentação em cena. Assim, nesta atividade, a oralidade é comtemplada. Novamente, nossa crítica recai sobre as necessidades das funções sociocomunicativas. Seria oportuna a sugestão de montagem de uma peça que pudesse ser apresentada, por exemplo, à comunidade escolar em momento de celebração na escola.

Da análise que fizemos, portanto, observamos que o LDP, ao contemplar gêneros textuais em suas propostas de escrita, os artificializa, transformando-os em exercícios para nota apenas, pois não leva em consideração o destinatário da atividade, para além do professor, e desconsidera as etapas no processo da escrita (planejamento, escrita e revisão), concedendo ao aluno a falsa impressão de que a boa escrita é possível numa primeira versão.

Entendemos que a crítica recorrente ao uso de textos como pretexto para exploração de questões gramaticais - casos em que, após um texto, seguem-se questões que ignoram a unidade de sentido, pois exploram frases pinçadas do texto como se a ele não pertencessem ocorre com o uso de gêneros textuais no material didático em análise. Esses estão, sim, presentes no livro didático, são explorados em algumas de suas características constitutivas, mas deles não decorrem propostas de atividades de uma língua-em-função, mas propostas que artificializam a escrita, o que nega o próprio conceito de gênero textual. 


\section{Conclusão}

Neste artigo, buscamos entender como os gêneros textuais são abordados no livro didático intitulado Língua Portuguesa- $12^{a}$ classe, utilizado nas escolas do Ensino Médio em Angola, a fim de refletirmos acerca de um dos objetivos da Reforma Educacional angolana: a melhoria da qualidade dos manuais escolares.

Centramos atenção no modo como o livro didático trabalha com o texto, se o trabalho proposto se alicerça sob o prisma dos gêneros. Inicialmente, apresentamos uma visão geral do livro didático e das unidades que o constituem. Nessa seção, notamos a predominância dos textos literários como base para as atividades de produção textual e entendemos que essa tônica deve-se à valoração que a Reforma Educacional angola concedeu à Literatura. Posteriormente, consideramos o conceito de gênero textual, bem como a relevância desse para o ensino de língua.

Ressaltamos, comopontospositivos, ainserção dediversos gêneros textuais no LDP em análise, bem como as atividades de compreensão leitora, pois essas embasam, de fato, as atividades de desenvolvimento da escrita, o que evidencia articulação entre as seções oficina de escrita e ler e compreender. Como negativos, destacamos os pontos referentes ao não detalhamento das características composicionais de vários gêneros solicitados nas atividades de escrita. Pontuamos também o fato de as sequências textuais, denominados de "protótipos textuais", serem apresentados na última seção do livro, essa divisão dificulta a percepção de que as sequências são constitutivas dos gêneros.

Da análise empreendida acerca da produção textual proposta no LDP, constatamos que as atividades não são condizentes com a perspectiva da língua-em-função, o que caracteriza os gêneros textuais, porque se prestam apenas à atribuição de notas, tendo como único leitor o professor. Entendemos que as atividades podem e devem ter função social, como afirma Geraldi (2003, p.162):

A exposição nas escolas, confecções de livros de histórias e organização de jornais escolares constituem atividades relevantes a serem desenvolvidas nas aulas de língua portuguesa de maneiras que, o trabalho com o gênero assuma uma função social.

Temos ciência de que o suporte, como bem explicita Marcuschi (2010), é fator importante na compreensão dos gêneros textuais. Assim, 
v. 7 (2) 517-533 ago/dez 2017

o fato de estar em livro didático já retira do gênero textual algumas de suas características. Trabalhar, por exemplo, um artigo de opinião no todo do jornal impresso ou virtual, em que ele efetivamente foi publicado, relacionando-o com os conteúdos dos demais gêneros veiculados naquele dia no suporte "jornal" é ideal. Desta feita, o fato de o gênero textual estar no livro didático já o artificializa. Mas entendemos que as propostas em torno dos gêneros contidos nos livros didáticos podem reconduzir os alunos aos suportes originais, podem e devem ser pensadas de modo a propiciar um trabalho com a língua-em-função.

Visto que não encontramos registros de trabalhos acadêmicos em Angola na perspectiva que aqui realizamos, voltados à análise de livros didáticos adotados em Angola à luz das teorias de gêneros textuais. Consideramos que esse estudo, embora introdutório, abre portas para outros trabalhos de análise de livros didáticos em espaços cuja língua oficial é a portuguesa. É pretensão nossa, por meio desta pesquisa e de estudos vindouros que almejamos empreender, contribuir para uma análise da adequação científica, pedagógica e metodológica dos materias didáticos que subsidiam o ensino e a aprendizagem da língua portuguesa em Angola, a fim de contribuir para o aprimoramento dos recursos didáticos adotados nesse país.

\section{Referências}

ANTUNeS, I. Aula de Português: encontro e interação-São Paulo: Parábola Editorial, 2003.

ANGOLA. Exame nacional 2015 da educação para todos: Angola. Incheon, 2014. Disponível em: http://unesdoc.unesco.org/images/0023/002317/231722por. pdf $>$. Acessado em 06. Nov. 2017.

ANGOLA. Lei n. 13/01, de 31 de dezembro de 2001. Lei de Bases do Sistema da Educação. Luanda: Assembleia Nacional, 2001.

ANGOLA, Ministério da Educação. Relatório da fase de experimentação do Ensino Primário e do $1^{0}$ Ciclo do Ensino Secundário. Luanda: Comissão de Acompanhamento das Acções da Reforma Educativa, 2010. Disponível em: <http://docplayer.com.br/49178498-Republica-de-angola-ministerioda-educacao-comissao-de-acompanhamento-das-accoes-da-reformaeducativa-caare-ficha-tecnica-coordenador-da-caare.html>. Acessado em 05. Nov.2017.

GARCIA NETO, C. O perfil linguístico e comunicativo dos alunos da escola de formação de professores Garcia Neto (Luanda-Angola). 2009. $139 f$. Dissertação (Mestrado em língua e cultura portuguesa) - Faculdade de Letras, Universidade de Lisboa, Lisboa. 2009.

GERALDI, J. W. Portos de passagem. 4. ed, São Paulo: Martins Fontes, 2003. 
MAGAlHÃES, O.; COSTA, F.; SILVA, L. Língua Portuguesa - $12^{\mathrm{a}}$ classe. Porto Editora, 2008.

MARCUSCHI, L., A. Gêneros textuais: definição e funcionalidade. In: DIONISIO, A.P.; MACHADO, A. R.; BEZERA, M. A ( Orgs ). Gêneros textuais \& ensino. São Paulo: Parábola Editorial, 2010.

ROJO, R.; BARBOSA, J. P. Hipermodalidade, multiletramentos e gêneros discursivos. $1^{\text {a }}$ ed, São Paulo: Parábola Editorial, 2015.

Recebido em: 21 de jun. de 2017.

Aceito em: 07 de nov. de 2017. 